\title{
Molecular mechanisms of somatostatin receptor trafficking
}

\author{
Zsolt Csaba $^{1,2}$, Stéphane Peineau ${ }^{1,2,3}$ and Pascal Dournaud ${ }^{1,2}$ \\ ${ }^{1}$ INSERM, Unité Mixte de Recherche U676, Paris, France \\ ${ }^{2}$ Université de Médecine Denis Diderot-Paris 7, Paris, France \\ ${ }^{3}$ Department of Anatomy, MRC Centre for Synaptic Plasticity, Bristol, UK \\ (Correspondence should be addressed to P Dournaud at INSERM, Unité Mixte de Recherche U676; Email: pascal.dournaud@inserm.fr)
}

\begin{abstract}
The neuropeptide somatostatin (SRIF) is an important modulator of neurotransmission in the central nervous system and acts as a potent inhibitor of hormone and exocrine secretion. In addition, SRIF regulates cell proliferation in normal and tumorous tissues. The six somatostatin receptor subtypes (sst1, sst2A, sst2B, sst3, sst4, and sst5), which belong to the G protein-coupled receptor (GPCR) family, share a common molecular topology: a hydrophobic core of seven transmembrane-spanning $\alpha$-helices, three intracellular loops, three extracellular loops, an amino-terminus outside the cell, and a carboxyl-terminus inside the cell. For most of the GPCRs, intracytosolic sequences, and more particularly the C-terminus, are believed to interact with proteins that are mandatory for either exporting neosynthesized receptor, anchoring receptor at the plasma membrane, internalization, recycling, or degradation after ligand binding. Accordingly, most of the SRIF receptors can traffic not only in vitro within different cell types but also in vivo. A picture of the pathways and proteins involved in these processes is beginning to emerge.
\end{abstract}

Journal of Molecular Endocrinology (2012) 48, R1-R12

\section{Trafficking: what does it mean for somato- statin receptors?}

Receptor export along the secretory pathway represents the first event in the trafficking of receptors within the cell and influences the proper delivery of functional receptors at the plasma membrane. As for other $G$ protein-coupled receptors (GPCRs), little is known about the mechanisms underlying somatostatin receptor export trafficking, although recent studies conducted in transfected cells have shed light on the potential proteins that could regulate sorting of the sst2A and sst5 receptors. By contrast, trafficking of somatostatin receptors after ligand binding (endocytosis, recycling, or degradation) has been well documented, first in transfected cell lines and primary cell cultures and more recently, in vivo, in a native environment. Among the six somatostatin receptors, endocytosis and trafficking of the sst2A receptor have been the most extensively studied because of its wide and strong expression in nervous, endocrine, and tumor tissues and the development of highly specific antibodies.

Agonist-induced internalization of SRIF receptors in cell lines has been recently reviewed (Csaba \&
Dournaud 2001, Tulipano \& Schulz 2007, Jacobs \& Schulz 2008). Differences between human and rodent SRIF receptor subtypes with respect to receptortrafficking properties, as well as the fact that the same receptor may differ in terms of trafficking depending on the cell type studied, are discussed in detail. In this review, we will therefore first focus on the recent progress made with respect to the intracellular trafficking of somatostatin receptor in vivo in different rodent and human tissues. We will then discuss the role of the different proteins that might be involved in export trafficking and receptor trafficking that follows internalization processes.

\section{Trafficking of somatostatin receptors: what is going on in the physiological context?}

The first evidence that somatostatin receptors might traffic in native cells came from the clinical cancer research field. Studies in the 1980 and early 1990s using in vitro receptor autoradiography have demonstrated a very high incidence and often a high density of somatostatin receptors in neuroendocrine and brain tumors, although receptor subtypes could not 
be precisely identified at that time (Reubi et al. 1987, 1990, 1991, 1992). Thanks to the cloning of somatostatin receptors, it was further demonstrated that the sst2A subtype is the most abundantly expressed receptor in the majority of tumors (Reubi et al. 1996, 1998, Hofland et al. 1999, Schulz et al. 2000b). A logical consequence of predominant somatostatin receptor expression was the development of radioactive ligands for diagnostic purposes such as ${ }^{111}$ In-DTPA-[D-Phe ${ }^{1}$ ] octreotide (Octreoscan; Reubi 2003, Weckbecker et al. 2003). A rapid uptake of ${ }^{111}$ In-radiolabeled somatostatin analogs by tumor cells allows the in vivo localization of tumors and their metastases for $24-48 \mathrm{~h}$ by $\delta$-camera scintigraphy (Reubi 2003, Weckbecker et al. 2003). This was supposed to be dependent on somatostatin receptor internalization, i.e. translocation of cell surface receptors to intracytoplasmic compartments and accumulation of radioactivity within the cell. In vivo trafficking of somatostatin receptors was first indicated by ultrastructural autoradiography in midgut carcinoid tumor tissues obtained from patients undergoing preoperative somatostatin receptor scintigraphy (Janson et al. 2000). Silver grains were seen not only at the plasma membrane but also in intracytoplasmic compartments as well as in perinuclear areas and nuclei. Additional confirmatory proofs were recently obtained using antibodies against the sst2A receptor in tumor samples from patients who were treated with various octreotide modalities before and during surgery and compared with tumor samples from untreated patients (Reubi et al. 2010). Patients receiving a high dose of octreotide showed predominantly internalized sst2A receptor in tumoral cells, and tumors from patients with a low dose had a variable ratio of internalized vs membranous sst2A receptor, whereas tumors of untreated patients had exclusively membrane-associated receptors. These observations provided evidence that sst2A receptor trafficking properties are likely to allow successful tumor imaging in patients, as well as targeted tumor radiotherapy. Interestingly, it also appears that endogenous somatostatin might induce sst2A receptor internalization in tumors since a preferentially cytoplasmic localization of the receptor was observed in tumors with a high level of somatostatin gene expression (pheochromocytoma and neuroblastoma), whereas in tumors lacking somatostatin mRNA (small-cell lung carcinoma, medulloblastoma, and paraganglioma), the receptor was preferentially membrane associated (Reubi et al. 2000). It is of note that radiolabeled somatostatin receptor antagonists were recently demonstrated to exhibit higher efficacy imaging properties than receptor agonists. Whereas agonists trigger strong internalization but bind to a limited number of receptors, antagonists lack internalization capabilities but appear to bind to a larger variety of receptor conformations (Ginj et al. 2006). The use of potent radiolabeled antagonists may therefore improve the sensitivity of tumor imaging and the efficacy of receptor-mediated targeted radiotherapy. Although, in addition to the sst2A subtype, other somatostatin receptors are expressed in human tumors (Kulaksiz et al. 2002, Ben-Shlomo \& Melmed 2010, Lupp et al. 2011), to our knowledge, in vivo receptor trafficking of these subtypes has not yet been documented.

Evidence that somatostatin receptors can traffic in vivo also comes from the neuroscience research field. Acute injections of octreotide in the deep layers of the cerebral cortex, hypothalamus, dorsolateral septum, or the hippocampus induce a massive redistribution of the sst2A receptor immunoreactivity in neuronal cells as demonstrated by confocal or electron microscopy (Csaba et al. 2001, 2002, 2003, 2007, Le Verche et al. 2009). A short time after agonist injection (5-10 $\mathrm{min})$, receptors translocate from the plasma membrane to endocytic vesicles in both cell bodies and dendrites, whereas in the long term after agonist challenge $(3-6 \mathrm{~h})$, dendrites are depleted in receptors, which accumulate in cell bodies. This retrograde transport was found to be dependent on the integrity of microtubules. At the level of the cell body, receptors are specifically targeted to a trans-Golgi network (TGN) compartment and are not visualized in the cis-Golgi, the endoplasmic reticulum, or degradative pathways. Receptors are then slowly recycled to the plasma membrane of both cell bodies and dendritic fields, where they are detected in amounts comparable to the pre-stimulation levels. These experiments have demonstrated for the first time that GPCR cargoes can recycle through the TGN after endocytosis. This long route might be necessary for biochemical modifications (glycosylation, palmitoylation, etc.) of recycled receptors and/or receptor interaction with escort/chaperone proteins and proper delivery to the plasma membrane (Duvernay et al. 2005). As hypothesized in several tumor types, different studies have provided evidence that endogenous brain somatostatin can also induce trafficking of somatostatin receptors. In the rat brain, the sst2A receptor was found to be mainly intracellular in regions receiving a dense SRIFergic innervation but more heavily surface bound in regions that receive a sparse SRIF innervation (Dournaud et al. 1998). Recently, the sst1 receptor was also found to be predominantly intracellular in GHRH-producing neurons of the arcuate nucleus of the hypothalamus, a neuronal population that receives a dense SRIF innervation (Stroh et al. 2009). In a rat model of middle cerebral artery occlusion, sst2A receptor internalization was observed in cerebrocortical neurons adjacent to the infarct (Stumm et al. 2004). This was associated with a 
transient and acute depletion of somatostatin from axonal terminals in the same regions. In the hippocampus of human and rat epileptic brains, sst2A receptor immunoreactivity was preserved in the inner, but decreased significantly in the outer, molecular layer of the dentate gyrus (Csaba et al. 2004, 2005). In this latter region, pronounced increase in SRIF immunoreactivity was observed. Decreased receptor density in epileptic tissues is likely to reflect internalization and slow recycling of sst2 receptors in response to high and chronic release of SRIF. Collectively, these studies tend to prove that SRIF released during physiological or pathophysiological conditions is able to regulate localization and trafficking of SRIF receptors.

\section{Trafficking of somatostatin receptors: which proteins might be involved?}

With the exception of the sst4 (Schreff et al. 2000), there is indeed ample evidence that membrane-associated somatostatin receptors internalize in vivo and/or in vitro after agonist stimulation. As for other GPCRs, these processes appear to be dependent on molecular mechanisms implying phosphorylation events and recruitment of $\beta$-arrestins. In Chinese hamster ovary $(\mathrm{CHO})$ cells stably transfected with the rat sst1 receptor, incubation with SRIF caused a rapid $(t 1 / 2<2 \mathrm{~min})$ increase in receptor phosphorylation in a dosedependent manner (Fig. 1; Liu \& Schonbrunn 2001). The protein kinase $\mathrm{C}$ (PKC), but not the PKA, could be involved in sst1 receptor phosphorylation events in this cell line. The inability of pertussis toxin to block SRIF-stimulated sst1 receptor phosphorylation suggests that agonist-stimulated phosphorylation is independent of receptor-G protein coupling, although receptor phosphorylation occurs concurrently with receptor desensitization. Whether phosphorylation is required for sst1 receptor internalization remains to be elucidated. Phosphorylation of sst2A receptor is also rapidly increased by agonist activation (Fig. 2). Several serine and threonine residues in the C-tail of the sst2A receptor are phosphorylated upon agonist stimulation, namely, Ser341, Ser343, Ser348, Thr353, and Thr354 in rat sst2A receptor transfected $\mathrm{CHO}$ and GH4C1 rat pituitary tumor cells (Liu et al. 2009), and Ser341, Ser343, Thr353, Thr354, Thr356, and T359 in HEK293 human embryonic kidney cells stably transfected with rat or human sst2A receptor (Nagel et al. 2011). Agonistdependent phosphorylation of the four Thr residues was also demonstrated in rat pituitary GH3 cells transiently transfected with rat sst2A receptor, rat pancreatic insulinoma INS1 cells, which endogenously express sst2A receptors, and in the rat pancreas in vivo (Poll et al. 2010). The Ser341 and Ser343 residues appear to be phosphorylated by $\mathrm{G}$ protein-coupled receptor kinase 2 (GRK2; Liu et al. 2009, Ghosh \& Schonbrunn 2011) or GRK3 (Nagel et al. 2011), whereas the threonine residues (Thr353, Thr354, Thr356, and Thr359) are phosphorylated by GRK2 and GRK3 (Poll et al. 2010). Compelling evidence suggests that phosphorylation of Thr residues is required for receptor internalization (Liu et al. 2008, 2009, Poll et al. 2010, Kao et al. 2011). In line with these findings, it was demonstrated that in a somatostatinoma, which synthesized and secreted SRIF and in which sst2A receptors are found to be intracellular, the receptors are phosphorylated. By contrast, in an ileal carcinoid tumor in which sst2A receptors are primarily at the cell surface, receptors do not appear to be phosphorylated (Liu et al. 2003). Heterologous regulation of somatostatin receptor 2 was also demonstrated. Bombesin and cholecystokinin induce phosphorylation of the sst2A receptor via PKC, and PKC activation potentiates internalization of the sst2A receptor in GH4C1 cells stably transfected with rat sst2A receptor and in AR42J rat pancreatic acinar cells expressing endogenous sst2A receptors (Hipkin et al. 1997, 2000, Elberg et al. 2002). PKC activation induces heterologous receptor phosphorylation in a cell-typespecific manner: both Ser343 and Ser348 are phosphorylated in GH4C1 cells, but only Ser343 is phosphorylated in CHO cells (Liu et al. 2009). The rat sst3 receptor also contains phosphate acceptor sites in the C-terminus (Ser341, Ser346, Ser351, and Thr357), which are essential for internalization and desensitization (Fig. 3; Roth et al. 1997b). In HEK cells stably transfected with rat sst3 receptor, SRIF induced sst3 receptor phosphorylation, which appears independent of the presence of overexpressed GRK2 (Roth et al. 1997 a, Tulipano et al. 2004). In human sst5 receptor transfected GH3 cells, agonist-dependent phosphorylation of the Ser242 residue of the third intracytoplasmic loop is crucial for receptor internalization (Fig. 4; Peverelli et al. 2008). The progressive truncation of the C-terminal tail of human sst5 receptor induces an increase in receptor internalization in GH3 cells (Peverelli et al. 2008) but a decrease in transfected CHO cells (Hukovic et al. 1998). Indeed, trafficking of SRIF receptors may vary between cell types and species, as previously reviewed (Csaba \& Dournaud 2001).

$\beta$-Arrestins were originally identified as negative regulators of GPCR signaling, including desensitization and internalization (DeFea 2011). Recent studies have revealed that $\beta$-arrestins also serve as intracellular scaffolds and signaling intermediates (DeFea 2011). Initial recruitment of arrestins by GPCRs requires the agonist-induced conformational change of the receptor, while receptor phosphorylation appears to be important for the stability of the arrestin/receptor complex (DeFea 2011). Class A GPCRs only transiently 


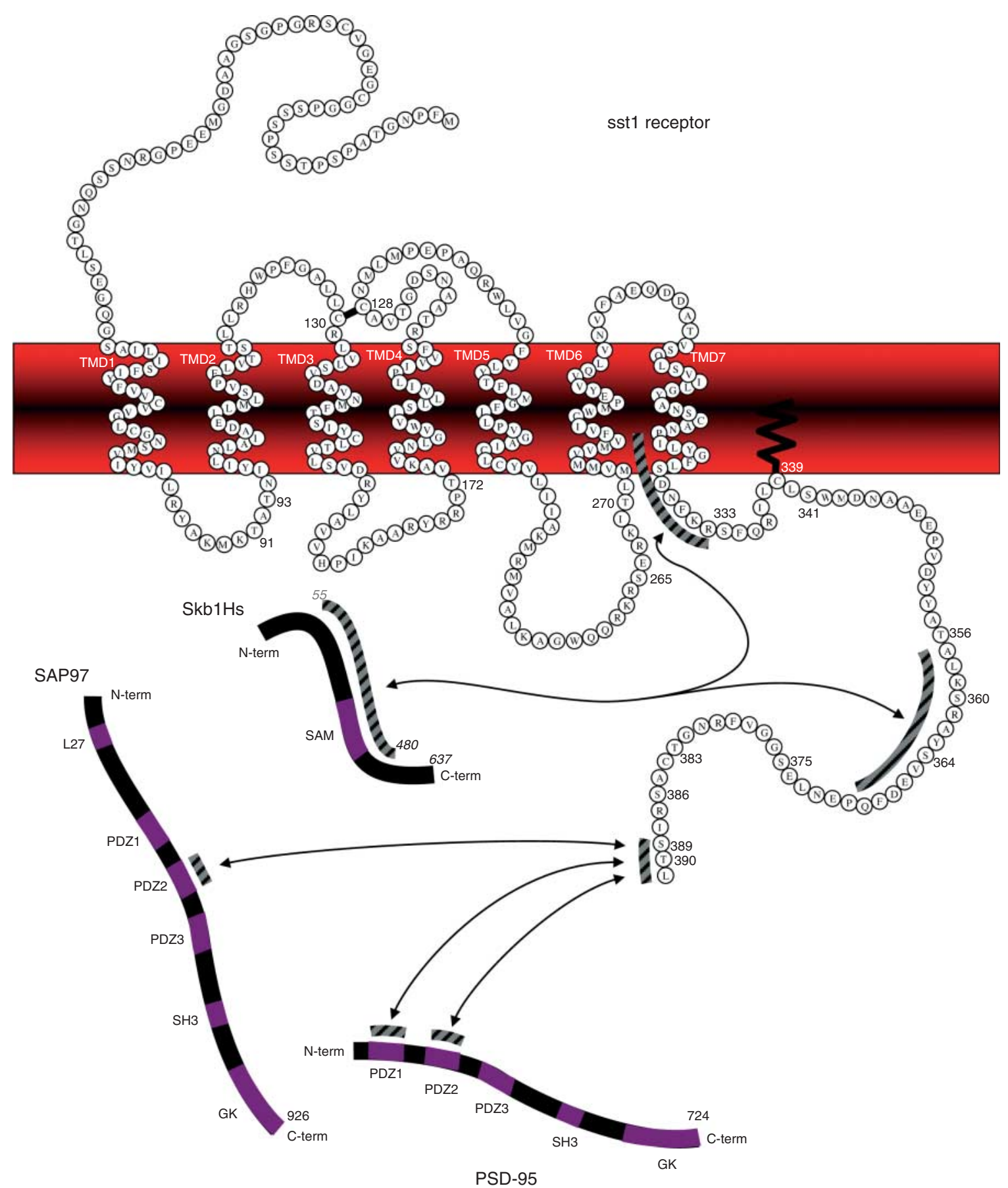

Figure 1 Rat sst1 receptor interactions and phosphorylation sites. The amino acids involved in the protein-protein interaction are indicated by gray bars. C-term, C-terminus; GK, guanylate kinase; N-term, N-terminus; PDZ, postsynaptic density-95/discs large/zonula occludens-1; PSD-95, postsynaptic density-95; SAM, sterile alpha motif; SAP97, synapse-associated protein 97; SH3, Src homology 3; TMD, transmembrane domain.

associate with $\beta$-arrestin, while class B GPCRs form more stable complexes. Among the somatostatin receptors that internalize, sst1 is the unique subtype that does not recruit $\beta$-arrestin 1 or 2 to the plasma membrane after agonist treatment (Tulipano et al. 2004). By contrast, in HEK cells (Tulipano et al. 2004), CHO cells (Liu et al. 2005), or primary hippocampal neurons (Lelouvier et al. 2008) co-transfected with $\beta$ 


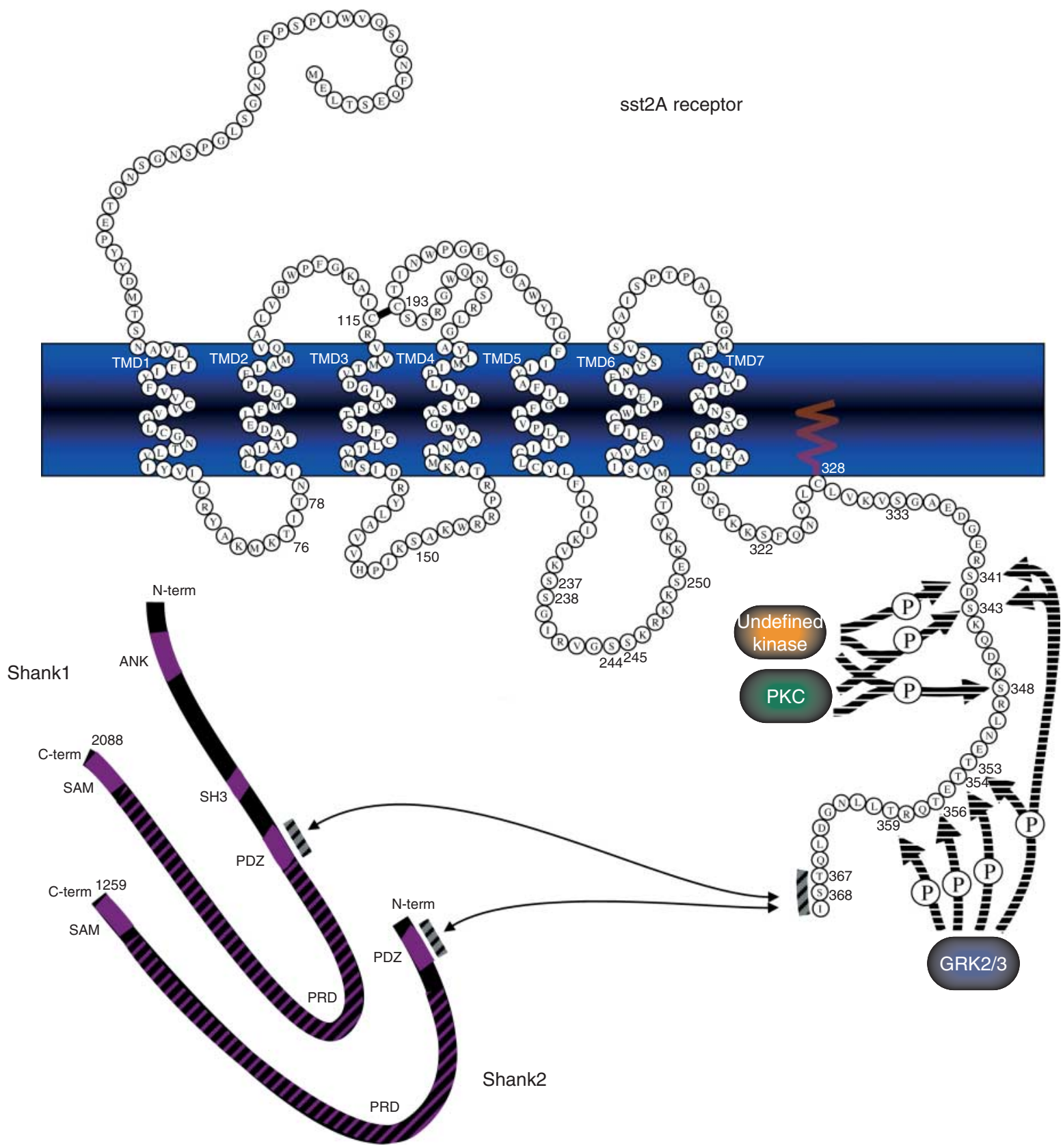

Figure 2 Rat sst2A receptor interactions and phosphorylation sites $(P)$. The amino acids involved in the protein-protein interaction are indicated by gray bars. The kinases able to phosphorylate the different sites are indicated. ANK, ankyrin repeats; C-term, C-terminus; GRK, G protein-coupled receptor kinase; N-term, N-terminus; PDZ, postsynaptic density-95/discs large/zonula occludens-1; PKC, protein kinase C; PRD, proline-rich domain; SAM, sterile alpha motif; SH3, Src homology 3; TMD, transmembrane domain.

arrestin-enhanced green fluorescent protein (EGFP) and the rat sst2A receptor, both $\beta$-arrestin 1 and $\beta$-arrestin 2 were recruited to the plasma membrane after agonist stimulation, formed stable complexes with the receptor, and internalized together (Fig. 5). Thus, the sst2A receptor is likely to belong to the class B GPCR subgroup. In HEK cells, the rat sst3 and sst5 receptors associate only transiently with both arrestins for the former and with only the $\beta$-arrestin 2 for the latter, indicating that both receptors exhibit a class A GPCR pattern (Tulipano et al. 2004). Following agonistinduced internalization, GPCRs either recycle back to the plasma membrane or are degraded. In contrast to the effective recycling of sst2A and sst5 receptors 


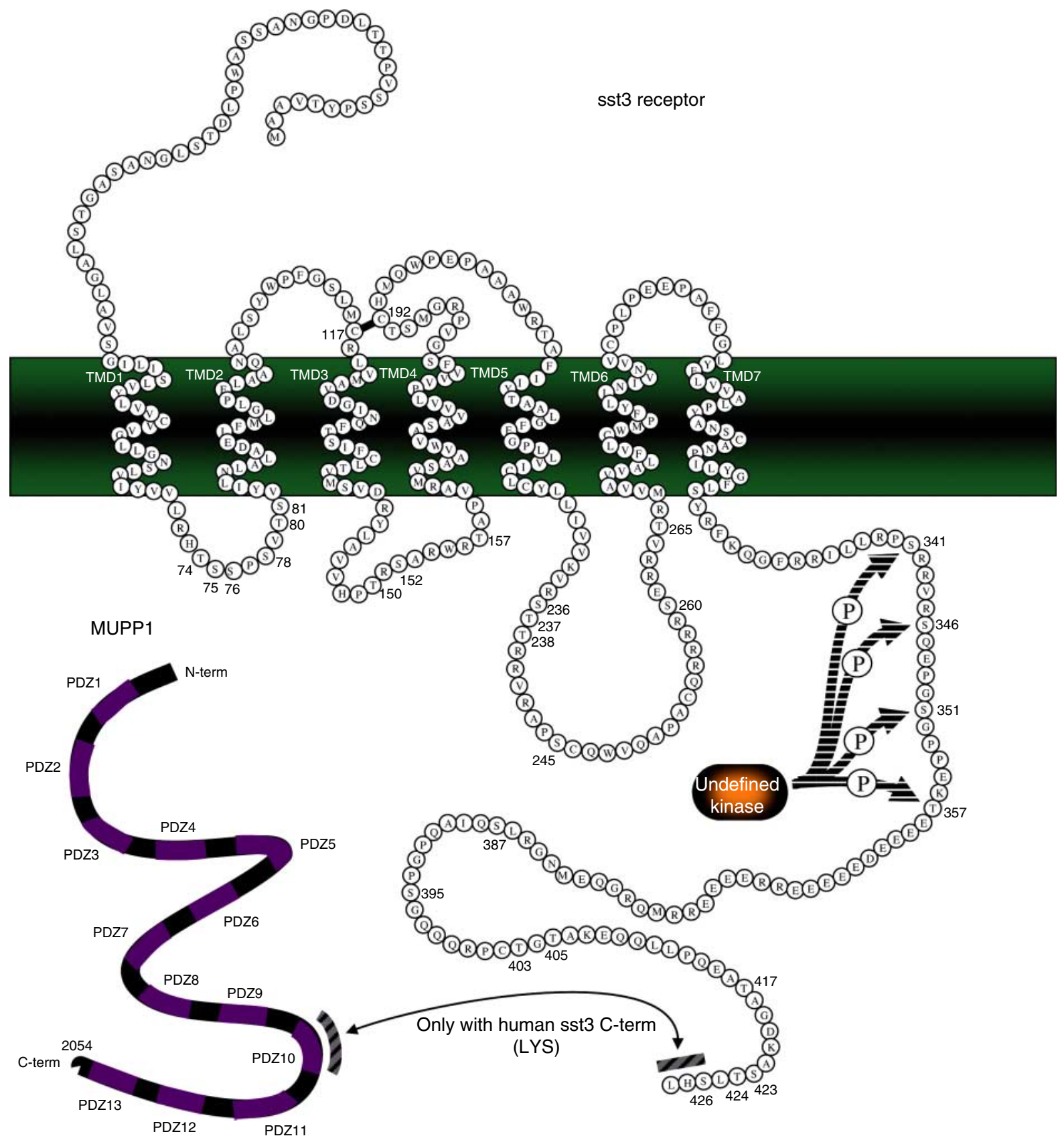

Figure 3 Rat sst3 receptor interactions and phosphorylation sites $(P)$. The amino acids involved in the protein-protein interaction are indicated by gray bars. C-term, C-terminus; MUPP1, multiple PDZ domain protein 1; N-term, N-terminus; PDZ, postsynaptic density-95/discs large/zonula occludens-1; TMD, transmembrane domain.

(Stroh et al. 2000, Csaba et al. 2007, Lelouvier et al. 2008, Lesche et al. 2009), a large proportion of sst3 receptors undergo ubiquitin-dependent lysosomal degradation that leads to pronounced down-regulation of this receptor subtype (Fig. 5; Kreuzer et al. 2001, Tulipano et al. 2004, Lesche et al. 2009).

All mammalian SRIF receptor subtypes, with the exception of the splice variant of the sst2 receptor, the
sst2B, contain a potential C-terminal class I postsynaptic density-95 (PSD-95)/discs large/zonula occludens-1 (PDZ) ligand motif (-Ser/Thr-X-Leu/Val/Ile). PDZ interactions are involved in the sorting, targeting, and assembly of various proteins including GPCRs (Sheng \& Sala 2001). Several studies have identified PDZ domain-containing proteins that interact with SRIF receptors, although the physiological relevance of these 


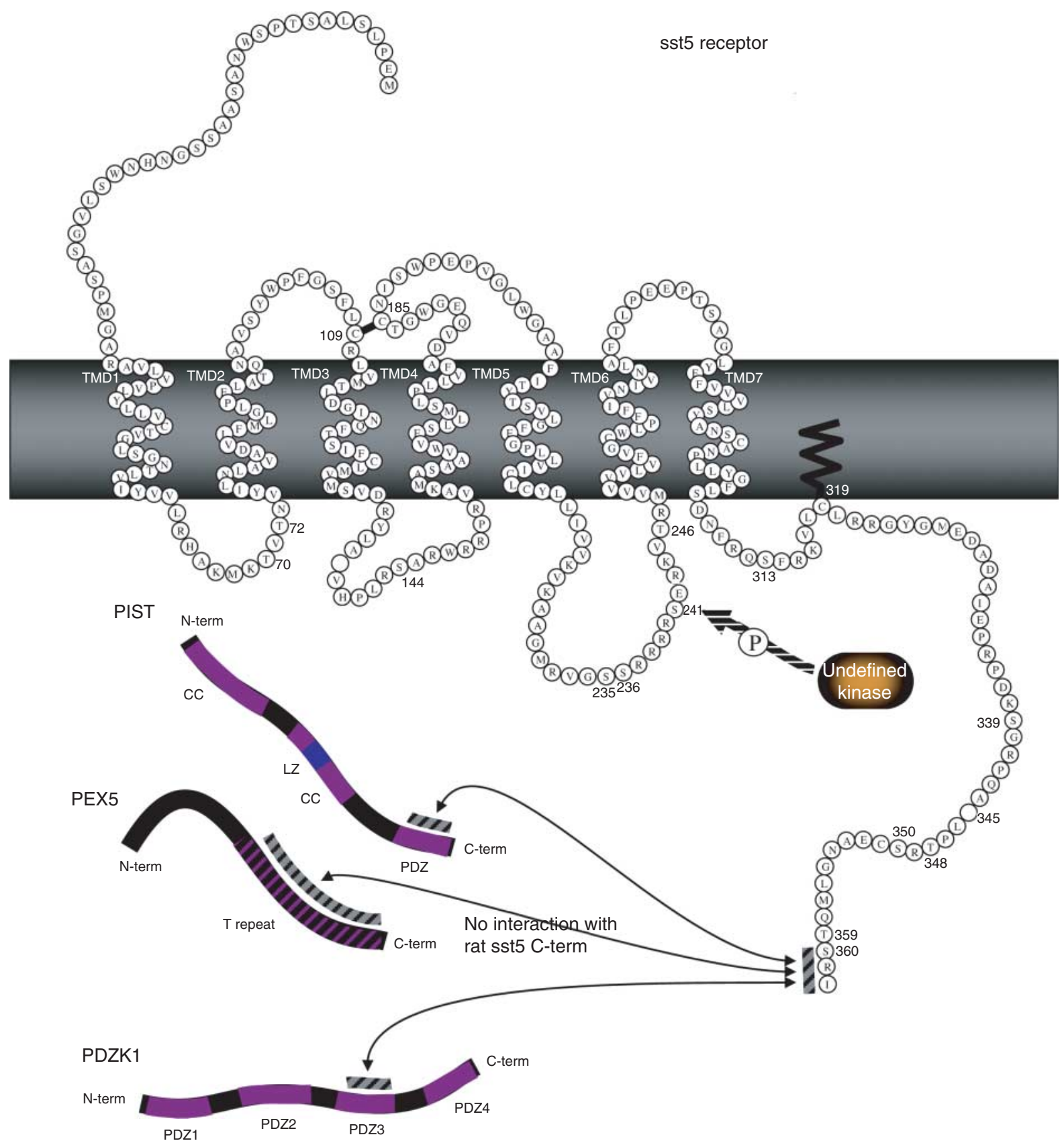

Figure 4 Rat sst5 receptor interactions and phosphorylation sites $(\mathrm{P})$. The amino acids involved in the protein-protein interaction are indicated by gray bars. Note that human sst5 receptor Ser242 corresponds to rat Ser241. C-term, C-terminus; CC, coiled coil; LZ, leucine zipper; N-term, N-terminus; PDZ, postsynaptic density-95/discs large/zonula occludens-1; PDZK1, PDZ protein expressed in kidney 1; PEX5, peroxisomal receptor; PIST, PDZ domain protein interacting specifically with TC10; T repeat, tetratricopeptide repeat; TMD, transmembrane domain.

interactions for receptor trafficking has yet to be specified.

The C-terminal tail of the sst1 receptor interacts with Skb1Hs (Fig. 1), the human homolog of the yeast Skb1 (Schwarzler et al. 2000). Both proteins belong to the protein methyltransferase superfamily. The full
C-terminus of sst1 receptor, as well as amino acid sequences close to or within the seventh transmembrane domain, and the full tertiary structure of the Skb1Hs are required for the protein interaction. In transfected HEK cells, Skb1Hs is intracellularly localized in unidentified compartments. When Skb1Hs 


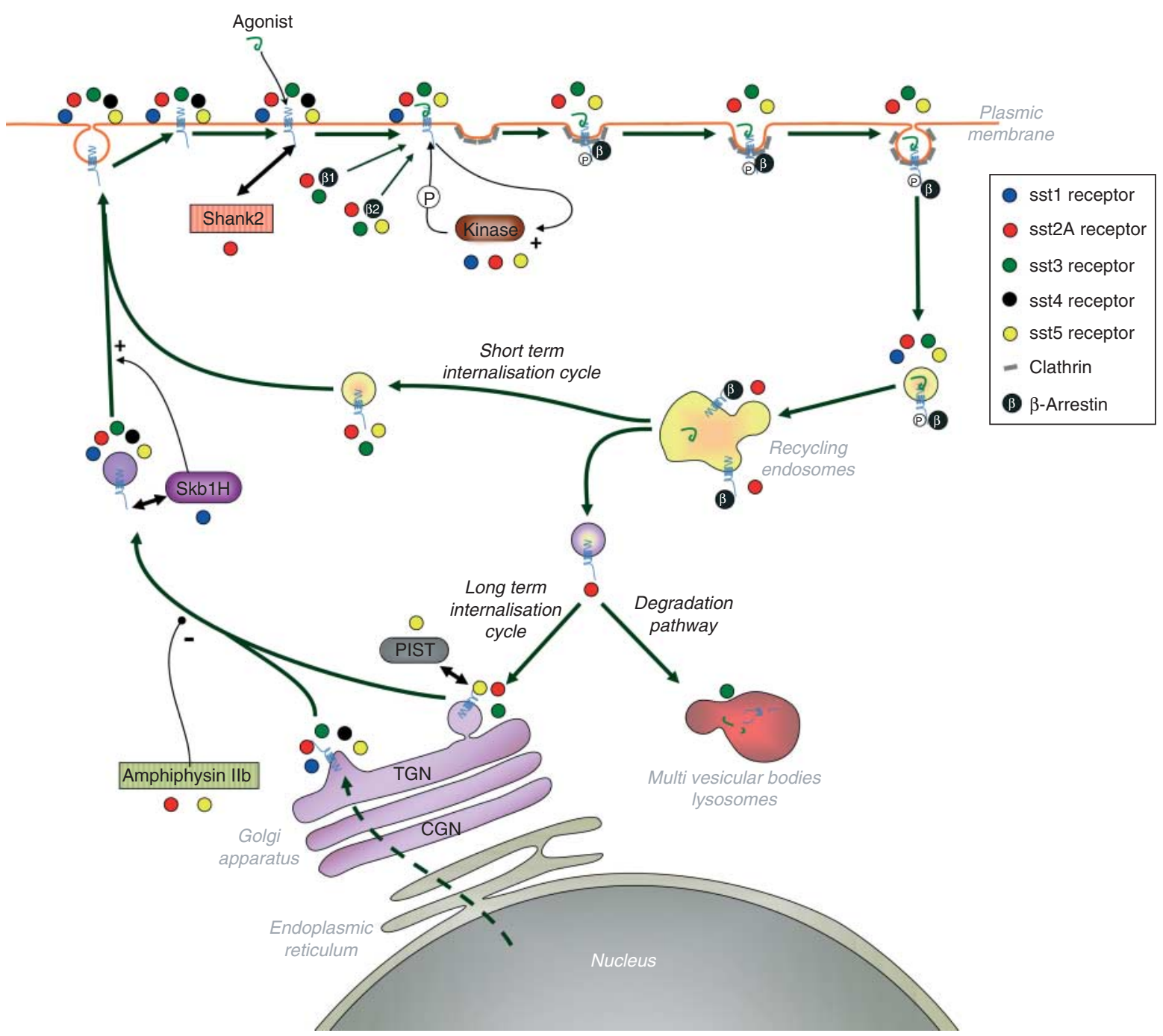

Figure 5 Somatostatin receptor trafficking after agonist stimulation. Following agonist binding, sst receptors 1 (blue), 2 (red), 3 (green), and 5 (yellow) activate kinase signaling pathways, leading to their self-phosphorylation and $\beta$-arrestin binding. Once phosphorylated, sst2, sst3, and sst5 receptors are internalized into clathrin-coated vesicles and addressed to endosomes. These receptors can then be either directly recycled to the plasma membrane (short-term internalization cycle) or addressed to a longterm internalization cycle via the TGN. Several proteins can interfere with the different steps of the receptor trafficking such as Skb1Hs that facilitates sst receptor targeting to the plasma membrane, amphiphysin Ilb that maintains sst receptors in intracellular compartment, or Shank2 that stabilizes sst receptors at the plasma membrane. The role of amphiphysin Ilb is not exclusive of sst receptors and could concern most of the proteins targeted from TGN to plasma membrane (Sarret et al. 2004). Among the sst receptors, only sst3 is targeted to the degradation pathway. CGN, cis-Golgi network; PIST, PDZ domain protein interacting specifically with teratocarcinoma clone number 10 (TC10).

was co-transfected with the sst1 receptor, the two proteins colocalized at the plasma membrane, although a pool of Skb1Hs was still present in the cytoplasm. Co-transfected cells displayed higher SRIF binding sites than HEK cells transfected only with the sst1 receptor. This suggests that Skb1Hs could target or anchor the sst1 receptor at the cell membrane (Fig. 5; Schwarzler et al. 2000). The C-terminus of the sst1 receptor is also a PDZ ligand for synapse-associated protein 97 (SAP97; Fig. 1), a protein that belongs to the PSD-95 family of membrane-associated guanylate kinase homologs (MAGUP). These synaptic scaffolding proteins are key players in the structural organization of the excitatory glutamatergic synapse. Interaction between native sst1 receptor and SAP97 was found by co-immunoprecipitation experiments in adult mouse brain (Cai et al. 2008). In transfected HEK cells, it was demonstrated that the C-terminal PDZ ligand motif of the sst1 receptor is required for such an interaction. However, PDZ motif deletion does not change the expression of the sst1 
receptor at the plasma membrane while the deletion of the full C-tail results in the trapping of the receptor in intracellular compartments. This suggests that interactions with SAP97 or with other PDZ proteins are not implicated in the targeting of the sst1 receptor to the cell surface, even though the sst1 receptor C-tail is required.

Using a yeast two-hybrid screen of a human cDNA library, the PDZ domain of somatostatin receptor interacting protein (SSTRIP), which is also known as SHANK1 and constitutes a major structural scaffolding protein of the postsynaptic density of excitatory synapses, specifically interacts with the C-terminal PDZ ligand of the sst2A receptor (Fig. 2; Zitzer et al. 1999a). Interestingly, sst2 receptor and SHANK1 (SSTRIP) mRNAs colocalized in the majority of brain areas, as demonstrated by in situ hybridization studies. Shank2, also termed cortactin-binding protein 1 (CortBP1) or proline-rich synapse-associated protein 1 (ProSAP1), also specifically interacts with the C-terminal PDZ ligand of the sst2A receptor (Fig. 2; Zitzer et al. 1999b). When Shank2/CortBP1 is expressed alone in HEK cells, its distribution is mainly cytoplasmic. When Shank2/ CortBP1 was coexpressed with the sst2A receptor, the two proteins colocalized at the plasma membrane (Fig. 5). This latter effect was increased after SRIF treatment, implying that the receptor agonist increased protein interactions, probably through conformational changes. As for Shank1, the distribution of Shank2, depicted by in situ hybridization, correlates well with that of sst2 receptor mRNAs in the rat brain.

Multiple PDZ domain protein 1 (MUPP1) was first identified as a protein interacting with type $2 \mathrm{C}$ serotonin receptor. It contains $13 \mathrm{PDZ}$ domains and acts as a scaffolding protein at tight junctions where it has been reported to interact with integral proteins, anchoring them to the F-actin cytoskeleton. A specific interaction between endogenous sst3 receptor and MUPP1 was demonstrated in human MCF-7 epithelial cells between the PDZ ligand of sst3 receptor and the PDZ domain 10 of MUPP1 (Fig. 3; Liew et al. 2009). In primary cultures of keratinocytes, the two proteins colocalized at cellular junctions. In sst3 receptor transfected Madin Darby canine kidney cells, receptors lacking the PDZ ligand domain are diffusely distributed throughout the cells whereas wild-type receptors are colocalized with MUPP1 at tight junctions (Liew et al. 2009). In neuronal cells, interactions between sst3 receptor and MUPP1 is not likely since MUPP1 is localized at postsynaptic sites while the sst3 receptor is preferentially targeted to neuronal cilia (Schulz et al. 2000a).

The PSD-95, which plays an important role in the organization of the postsynaptic specialization of excitatory synapses, interacts via its PDZ domain 2 with the C-terminal of the rat sst1 and sst 4 receptors
(Fig. 1; Christenn et al. 2007). The existence of sst4 receptor/PSD-95 complex was verified by co-immunoprecipitation experiments from transfected HEK cells and solubilized mouse brain membranes. In primary neurons, sst 4 receptor partially colocalized with PSD-95 clusters in dendrites, indicating that the role of this interaction could be to anchor the sst4 receptor to postsynaptic sites in neuronal cells.

The protein PIST (PDZ domain protein interacting specifically with teratocarcinoma clone number 10), which is highly expressed in brain and periphery and is mainly localized in the Golgi/TGN, interacts through its unique PDZ domain with the PDZ ligand motifs of both human and rat sst5 receptors (Fig. 4; Wente et al. 2005). Co-transfection of PIST with the sst5 receptor in HEK cells changes the localization of the receptor from the membrane to the Golgi/TGN compartment, while an sst5 mutant receptor, lacking the PDZ ligand motif, is found at the cell membrane. Interestingly, in HEK cells that do not overexpress PIST, wild-type sst5 receptors activated by a specific ligand are targeted to the Golgi apparatus before being recycled to the plasma membrane, while receptors without the PDZ domain lack the ability to be recycled. This suggests that after endocytosis, the sst5 receptor PDZ-binding domain is indeed necessary for the proper delivery of receptors to the plasma membrane. In mouse pituitary AtT20 cells, which endogenously express the sst5 receptor, both PIST and sst5 receptor are colocalized in the Golgi/ TGN. Although these experiments do not prove that PIST carries the receptor from the Golgi to the plasma membrane, it can be hypothesized that this protein might be, at least, implicated in the trafficking of the sst5 receptor in the Golgi apparatus (Fig. 5). The rat and human sst5 receptor also interacts via PDZ domaintype interaction with PDZ protein expressed in kidney 1 (PDZK1; Fig. 4), which regulates membrane localization of ion channels and transporters in the kidney and small intestines (Wente et al. 2005). Both proteins colocalized at the membrane of transfected HEK cells, suggesting that PDZK1 could anchor the sst5 receptor in endocrine cells. Finally, physical interaction between the human and mouse (but not rat) sst5 receptors and the peroxisomal receptor PEX5 was found in transfected HEK cells (Fig. 4; Wente et al. 2005). Since there is no evidence for peroxisomal targeting of sst5 receptor in these cells, this suggests that additional factors besides the C-terminal motif are required to target a membrane protein to peroxisomes. On the other hand, one can hypothesize that PEX5 participates in as-yet unknown signaling events.

The homo- and heterodimerization of SRIF receptors were recently reviewed in detail (Duran-Prado et al. 2008). However, the molecular mechanisms by which dimerization affects receptor trafficking have not yet been elucidated. 


\section{Concluding remarks}

Important progress has been made in the field of somatostatin receptor trafficking in recent years. Increasing details of how SRIF receptors are removed from the plasma membrane have been elucidated in vitro, and more importantly in a physiological context. Details of how SRIF receptors travel and recycle following internalization have also shed light on the importance of such mechanisms for the diagnosis and treatment of tumors, and the pathophysiology of epilepsies. Although these advances are impressive, more work is needed to identify SRIF receptors' protein partners and analyze their exact role in trafficking and recycling. This is of particular importance to better understand SRIF physiology and to design therapeutic strategies to target this subclass of GPCR.

\section{Declaration of interest}

The authors declare that there is no conflict of interest that could be perceived as prejudicing the impartiality of the research reported.

\section{Funding}

This work was supported by the Institut National de la Santé et de la Recherche Médicale (INSERM), Université Denis Diderot-Paris 7, Assistance Publique - Hôpitaux de Paris (AP-HP; Contrat d'Interface to Dr Pascal Dournaud), Association pour la Recherche sur le Cancer (ARC), and Fédération pour la Recherche sur le Cerveau (FRC). Dr Stéphane Peineau was supported by the Medical Research Council (UK).

\section{References}

Ben-Shlomo A \& Melmed S 2010 Pituitary somatostatin receptor signaling. Trends in Endocrinology and Metabolism 21 123-133. (doi:10. 1016/j.tem.2009.12.003)

Cai C, Li H, Kangasniemi A, Pihlajamaa T, Von Ossowski L, Kerkela K, Schulz S, Rivera C \& Keinanen K 2008 Somatostatin receptor subtype 1 is a PDZ ligand for synapse-associated protein 97 and a potential regulator of growth cone dynamics. Neuroscience $\mathbf{1 5 7}$ 833-843. (doi:10.1016/j.neuroscience.2008.09.048)

Christenn M, Kindler S, Schulz S, Buck F, Richter D \& Kreienkamp HJ 2007 Interaction of brain somatostatin receptors with the PDZ domains of PSD-95. FEBS Letters 581 5173-5177. (doi:10.1016/ j.febslet.2007.10.003)

Csaba Z \& Dournaud P 2001 Cellular biology of somatostatin receptors. Neuropeptides 35 1-23. (doi:10.1054/npep.2001.0848)

Csaba Z, Bernard V, Helboe L, Bluet-Pajot MT, Bloch B, Epelbaum J \& Dournaud P 2001 In vivo internalization of the somatostatin sst2A receptor in rat brain: evidence for translocation of cell-surface receptors into the endosomal recycling pathway. Molecular and Cellular Neurosciences 17 646-661. (doi:10.1006/mcne.2000.0958)

Csaba Z, Simon A, Helboe L, Epelbaum J \& Dournaud P 2002 Neurochemical characterization of receptor-expressing cell populations by in vivo agonist-induced internalization: insights from the somatostatin sst2A receptor. Journal of Comparative Neurology 454 192-199. (doi:10.1002/cne.10430)
Csaba Z, Simon A, Helboe L, Epelbaum J \& Dournaud P 2003 Targeting sst2A receptor-expressing cells in the rat hypothalamus through in vivo agonist stimulation: neuroanatomical evidence for a major role of this subtype in mediating somatostatin functions. Endocrinology 144 1564-1573. (doi:10.1210/en.2002-221090)

Csaba Z, Richichi C, Bernard V, Epelbaum J, Vezzani A \& Dournaud P 2004 Plasticity of somatostatin and somatostatin sst2A receptors in the rat dentate gyrus during kindling epileptogenesis. European Journal of Neuroscience 19 2531-2538. (doi:10.1111/j.0953-816X. 2004.03361.x)

Csaba Z, Pirker S, Lelouvier B, Simon A, Videau C, Epelbaum J, Czech T, Baumgartner C, Sperk G \& Dournaud P 2005 Somatostatin receptor type 2 undergoes plastic changes in the human epileptic dentate gyrus. Journal of Neuropathology and Experimental Neurology 64 956-969. (doi:10.1097/01.jnen.0000186923.50215.50)

Csaba Z, Lelouvier B, Viollet C, El Ghouzzi V, Toyama K, Videau C, Bernard V \& Dournaud P 2007 Activated somatostatin type 2 receptors traffic in vivo in central neurons from dendrites to the trans Golgi before recycling. Traffic 8 820-834. (doi:10.1111/j.16000854.2007.00580.x)

DeFea KA 2011 Beta-arrestins as regulators of signal termination and transduction: how do they determine what to scaffold? Cellular Signalling 23 621-629. (doi:10.1016/j.cellsig.2010.10.004)

Dournaud P, Boudin H, Schonbrunn A, Tannenbaum GS \& Beaudet A 1998 Interrelationships between somatostatin sst2A receptors and somatostatin-containing axons in rat brain: evidence for regulation of cell surface receptors by endogenous somatostatin. Journal of Neuroscience 18 1056-1071.

Duran-Prado M, Malagon MM, Gracia-Navarro F \& Castano JP 2008 Dimerization of $\mathrm{G}$ protein-coupled receptors: new avenues for somatostatin receptor signalling, control and functioning. Molecular and Cellular Endocrinology 286 63-68. (doi:10.1016/j.mce.2007.12. 006)

Duvernay MT, Filipeanu CM \& Wu G 2005 The regulatory mechanisms of export trafficking of $\mathrm{G}$ protein-coupled receptors. Cellular Signalling 17 1457-1465. (doi:10.1016/j.cellsig.2005.05.020)

Elberg G, Hipkin RW \& Schonbrunn A 2002 Homologous and heterologous regulation of somatostatin receptor 2. Molecular Endocrinology 16 2502-2514. (doi:10.1210/me.2002-0207)

Ghosh M \& Schonbrunn A 2011 Differential temporal and spatial regulation of somatostatin receptor phosphorylation and dephosphorylation. Journal of Biological Chemistry 286 13561-13573. (doi:10.1074/jbc.M110.215723)

Ginj M, Zhang H, Waser B, Cescato R, Wild D, Wang X, Erchegyi J, Rivier J, Macke HR \& Reubi JC 2006 Radiolabeled somatostatin receptor antagonists are preferable to agonists for in vivo peptide receptor targeting of tumors. PNAS 103 16436-16441. (doi:10. 1073/pnas.0607761103)

Hipkin RW, Friedman J, Clark RB, Eppler CM \& Schonbrunn A 1997 Agonist-induced desensitization, internalization, and phosphorylation of the sst2A somatostatin receptor. Journal of Biological Chemistry 272 13869-13876. (doi:10.1074/jbc.272.21.13869)

Hipkin RW, Wang Y \& Schonbrunn A 2000 Protein kinase C activation stimulates the phosphorylation and internalization of the sst2A somatostatin receptor. Journal of Biological Chemistry 275 5591-5599. (doi:10.1074/jbc.275.8.5591)

Hofland LJ, Liu Q, Van Koetsveld PM, Zuijderwijk J, Van Der Ham F, De Krijger RR, Schonbrunn A \& Lamberts SW 1999 Immunohistochemical detection of somatostatin receptor subtypes sstl and sst2A in human somatostatin receptor positive tumors. Journal of Clinical Endocrinology and Metabolism 84 775-780. (doi:10.1210/jc.84. 2.775)

Hukovic N, Panetta R, Kumar U, Rocheville M \& Patel YC 1998 The cytoplasmic tail of the human somatostatin receptor type 5 is crucial for interaction with adenylyl cyclase and in mediating desensitization and internalization. Journal of Biological Chemistry 273 21416-21422. (doi:10.1074/jbc.273.33.21416) 
Jacobs S \& Schulz S 2008 Intracellular trafficking of somatostatin receptors. Molecular and Cellular Endocrinology 286 58-62. (doi:10. 1016/j.mce.2007.10.005)

Janson ET, Westlin JE, Ohrvall U, Oberg K \& Lukinius A 2000 Nuclear localization of ${ }^{111}$ In after intravenous injection of $\left[{ }^{111}\right.$ In-DTPA-D$\left.\mathrm{Phe}^{1}\right]$-octreotide in patients with neuroendocrine tumors. Journal of Nuclear Medicine 41 1514-1518.

Kao YJ, Ghosh M \& Schonbrunn A 2011 Ligand-dependent mechanisms of sst2A receptor trafficking: role of site-specific phosphorylation and receptor activation in the actions of biased somatostatin agonists. Molecular Endocrinology 25 1040-1054. (doi:10.1210/me.2010-0398)

Kreuzer OJ, Krisch B, Dery O, Bunnett NW \& Meyerhof W 2001 Agonistmediated endocytosis of rat somatostatin receptor subtype 3 involves beta-arrestin and clathrin coated vesicles. Journal of Neuroendocrinology 13 279-287. (doi:10.1046/j.1365-2826.2001.00630.x)

Kulaksiz H, Eissele R, Rossler D, Schulz S, Hollt V, Cetin Y \& Arnold R 2002 Identification of somatostatin receptor subtypes 1, 2A, 3, and 5 in neuroendocrine tumours with subtype specific antibodies. Gut $\mathbf{5 0}$ 52-60. (doi:10.1136/gut.50.1.52)

Lelouvier B, Tamagno G, Kaindl AM, Roland A, Lelievre V, Le Verche V, Loudes C, Gressens P, Faivre-Baumann A, Lenkei Z et al. 2008 Dynamics of somatostatin type $2 \mathrm{~A}$ receptor cargoes in living hippocampal neurons. Journal of Neuroscience 28 4336-4349. (doi:10.1523/JNEUROSCI.4379-07.2008)

Lesche S, Lehmann D, Nagel F, Schmid HA \& Schulz S 2009 Differential effects of octreotide and pasireotide on somatostatin receptor internalization and trafficking in vitro. Journal of Clinical Endocrinology and Metabolism 94 654-661. (doi:10.1210/jc.2008-1919)

Le Verche V, Kaindl AM, Verney C, Csaba Z, Peineau S, Olivier P, Adle-Biassette H, Leterrier C, Vitalis T, Renaud J et al. 2009 The somatostatin $2 \mathrm{~A}$ receptor is enriched in migrating neurons during rat and human brain development and stimulates migration and axonal outgrowth. PLoS ONE 4 e5509. (doi:10.1371/journal.pone.0005509)

Liew CW, Vockel M, Glassmeier G, Brandner JM, Fernandez-Ballester GJ, Schwarz JR, Schulz S, Buck F, Serrano L, Richter D et al. 2009 Interaction of the human somatostatin receptor 3 with the multiple PDZ domain protein MUPP1 enables somatostatin to control permeability of epithelial tight junctions. FEBS Letters $\mathbf{5 8 3} 49-54$. (doi:10.1016/j.febslet.2008.11.048)

Liu Q 2001 Agonist-induced phosphorylation of somatostatin receptor subtype 1 (sst1). Relationship to desensitization and internalization. Journal of Biological Chemistry 276 3709-3717. (doi:10.1074/ jbc.M008873200)

Liu Q, Reubi JC, Wang Y, Knoll BJ \& Schonbrunn A 2003 In vivo phosphorylation of the somatostatin 2A receptor in human tumors. Journal of Clinical Endocrinology and Metabolism 88 6073-6079. (doi:10.1210/jc.2003-030986)

Liu Q, Cescato R, Dewi DA, Rivier J, Reubi JC \& Schonbrunn A 2005 Receptor signaling and endocytosis are differentially regulated by somatostatin analogs. Molecular Pharmacology 68 90-101. (doi:10. 1124/mol.105.011767)

Liu Q, Dewi DA, Liu W, Bee MS \& Schonbrunn A 2008 Distinct phosphorylation sites in the SST2A somatostatin receptor control internalization, desensitization, and arrestin binding. Molecular Pharmacology 73 292-304. (doi:10.1124/mol.107.038570)

Liu Q, Bee MS \& Schonbrunn A 2009 Site specificity of agonist and second messenger-activated kinases for somatostatin receptor subtype 2A (Sst2A) phosphorylation. Molecular Pharmacology 76 68-80. (doi:10.1124/mol.108.054262)

Lupp A, Hunder A, Petrich A, Nagel F, Doll C \& Schulz S 2011 Reassessment of sst(5) somatostatin receptor expression in normal and neoplastic human tissues using the novel rabbit monoclonal antibody UMB-4. Neuroendocrinology 94 255-264. (doi:10.1159/000329876)

Nagel F, Doll C, Poll F, Kliewer A, Schroder H \& Schulz S 2011 Structural determinants of agonist-selective signaling at the sst2A somatostatin receptor. Molecular Endocrinology 25 859-866. (doi:10. $1210 /$ me.2010-0407)
Peverelli E, Mantovani G, Calebiro D, Doni A, Bondioni S, Lania A, Beck-Peccoz P \& Spada A 2008 The third intracellular loop of the human somatostatin receptor 5 is crucial for arrestin binding and receptor internalization after somatostatin stimulation. Molecular Endocrinology 22 676-688. (doi:10.1210/me.2007-0068)

Poll F, Lehmann D, Illing S, Ginj M, Jacobs S, Lupp A, Stumm R \& Schulz S 2010 Pasireotide and octreotide stimulate distinct patterns of sst2A somatostatin receptor phosphorylation. Molecular Endocrinology 24 436-446. (doi:10.1210/me.2009-0315)

Reubi JC 2003 Peptide receptors as molecular targets for cancer diagnosis and therapy. Endocrine Reviews 24 389-427. (doi:10.1210/ er.2002-0007)

Reubi JC, Maurer R, von Werder K, Torhorst J, Klijn JG \& Lamberts SW 1987 Somatostatin receptors in human endocrine tumors. Cancer Research 47 551-558.

Reubi JC, Krenning E, Lamberts SW \& Kvols L 1990 Somatostatin receptors in malignant tissues. Journal of Steroid Biochemistry and Molecular Biology 37 1073-1077. (doi:10.1016/0960-0760 (90)90468-Z)

Reubi JC, Kvols L, Krenning E \& Lamberts SW 1991 In vitro and in vivo detection of somatostatin receptors in human malignant tissues. Acta Oncologica 30 463-468. (doi:10.3109/02841869109092402)

Reubi JC, Laissue J, Krenning E \& Lamberts SW 1992 Somatostatin receptors in human cancer: incidence, characteristics, functional correlates and clinical implications. Journal of Steroid Biochemistry and Molecular Biology 43 27-35. (doi:10.1016/0960-0760(92)90184-K)

Reubi JC, Schaer JC, Laissue JA \& Waser B 1996 Somatostatin receptors and their subtypes in human tumors and in peritumoral vessels. Metabolism 45 39-41. (doi:10.1016/S0026-0495(96)90077-3)

Reubi JC, Kappeler A, Waser B, Laissue J, Hipkin RW \& Schonbrunn A 1998 Immunohistochemical localization of somatostatin receptors sst2A in human tumors. American Journal of Pathology 153 233-245. (doi:10.1016/S0002-9440(10)65564-2)

Reubi JC, Waser B, Liu Q, Laissue JA \& Schonbrunn A 2000 Subcellular distribution of somatostatin sst2A receptors in human tumors of the nervous and neuroendocrine systems: membranous versus intracellular location. Journal of Clinical Endocrinology and Metabolism 85 3882-3891. (doi:10.1210/jc.85.10.3882)

Reubi JC, Waser B, Cescato R, Gloor B, Stettler C \& Christ E 2010 Internalized somatostatin receptor subtype 2 in neuroendocrine tumors of octreotide-treated patients. Journal of Clinical Endocrinology and Metabolism 95 2343-2350. (doi:10.1210/jc.2009-2487)

Roth A, Kreienkamp HJ, Meyerhof W \& Richter D $1997 a$ Phosphorylation of four amino acid residues in the carboxyl terminus of the rat somatostatin receptor subtype 3 is crucial for its desensitization and internalization. Journal of Biological Chemistry 272 23769-23774. (doi:10.1074/jbc.272.38.23769)

Roth A, Kreienkamp HJ, Nehring RB, Roosterman D, Meyerhof W \& Richter D $1997 b$ Endocytosis of the rat somatostatin receptors: subtype discrimination, ligand specificity, and delineation of carboxy-terminal positive and negative sequence motifs. DNA and Cell Biology 16 111-119. (doi:10.1089/dna.1997.16.111)

Sarret P, Esdaile MJ, McPherson PS, Schonbrunn A, Kreienkamp HJ \& Beaudet A 2004 Role of amphiphysin II in somatostatin receptor trafficking in neuroendocrine cells. Journal of Biological Chemistry 279 8029-8037. (doi:10.1074/jbc.M310792200)

Schreff M, Schulz S, Handel M, Keilhoff G, Braun H, Pereira G, Klutzny M, Schmidt H, Wolf G \& Hollt V 2000 Distribution, targeting, and internalization of the sst 4 somatostatin receptor in rat brain. Journal of Neuroscience 20 3785-3797.

Schulz S, Handel M, Schreff M, Schmidt H \& Hollt V 2000a Localization of five somatostatin receptors in the rat central nervous system using subtype-specific antibodies. Journal of Physiology (Paris) 94 259-264. (doi:10.1016/S0928-4257(00)00212-6)

Schulz S, Pauli SU, Handel M, Dietzmann K, Firsching R \& Hollt V $2000 \mathrm{~b}$ Immunohistochemical determination of five somatostatin receptors in meningioma reveals frequent overexpression of somatostatin receptor subtype sst2A. Clinical Cancer Research 6 $1865-1874$ 
Schwarzler A, Kreienkamp HJ \& Richter D 2000 Interaction of the somatostatin receptor subtype 1 with the human homolog of the Shk1 kinase-binding protein from yeast. Journal of Biological Chemistry 275 9557-9562. (doi:10.1074/jbc.275.13.9557)

Sheng M \& Sala C 2001 PDZ domains and the organization of supramolecular complexes. Annual Review of Neuroscience 24 1-29. (doi:10.1146/annurev.neuro.24.1.1)

Stroh T, Jackson AC, Sarret P, Dal Farra C, Vincent JP, Kreienkamp HJ, Mazella J \& Beaudet A 2000 Intracellular dynamics of sst5 receptors in transfected COS-7 cells: maintenance of cell surface receptors during ligand-induced endocytosis. Endocrinology 141 354-365. (doi:10.1210/en.141.1.354)

Stroh T, van Schouwenburg MR, Beaudet A \& Tannenbaum GS 2009 Subcellular dynamics of somatostatin receptor subtype 1 in the rat arcuate nucleus: receptor localization and synaptic connectivity vary in parallel with the ultradian rhythm of growth hormone secretion. Journal of Neuroscience 29 8198-8205. (doi:10.1523/JNEUROSCI. 0336-09.2009)

Stumm RK, Zhou C, Schulz S, Endres M, Kronenberg G, Allen JP, Tulipano G \& Hollt V 2004 Somatostatin receptor 2 is activated in cortical neurons and contributes to neurodegeneration after focal ischemia. Journal of Neuroscience 24 11404-11415. (doi:10.1523/ JNEUROSCI.3834-04.2004)

Tulipano G \& Schulz S 2007 Novel insights in somatostatin receptor physiology. European Journal of Endocrinology 156 (Suppl 1) S3-S11. (doi:10.1530/eje.1.02354)
Tulipano G, Stumm R, Pfeiffer M, Kreienkamp HJ, Hollt V \& Schulz S 2004 Differential beta-arrestin trafficking and endosomal sorting of somatostatin receptor subtypes. Journal of Biological Chemistry 279 21374-21382. (doi:10.1074/jbc.M313522200)

Weckbecker G, Lewis I, Albert R, Schmid HA, Hoyer D \& Bruns C 2003 Opportunities in somatostatin research: biological, chemical and therapeutic aspects. Nature Reviews. Drug Discovery 2 999-1017. (doi:10.1038/nrd1255)

Wente W, Stroh T, Beaudet A, Richter D \& Kreienkamp HJ 2005 Interactions with PDZ domain proteins PIST/GOPC and PDZK1 regulate intracellular sorting of the somatostatin receptor subtype 5. Journal of Biological Chemistry 280 32419-32425. (doi:10.1074/jbc. M507198200)

Zitzer H, Honck HH, Bachner D, Richter D \& Kreienkamp HJ 1999a Somatostatin receptor interacting protein defines a novel family of multidomain proteins present in human and rodent brain. Journal of Biological Chemistry 274 32997-33001. (doi:10.1074/jbc. 274.46.32997)

Zitzer H, Richter D \& Kreienkamp HJ 1999b Agonist-dependent interaction of the rat somatostatin receptor subtype 2 with cortactin-binding protein 1. Journal of Biological Chemistry 274 18153-18156. (doi:10.1074/jbc.274.26.18153)

Received in final form 10 November 2011

Accepted 12 December 2011

Made available online as an Accepted Preprint 12 December 2011 